\title{
EXPLORANDO UMA NOVA DIMENSÃO BIOPOLÍTICA DO CORPO ENCARCERADO: CONTROVÉRSIAS EM TORNO DA LEI FEDERAL N. ${ }^{\circ} 12.654 / 2012$
}

\author{
Marcelo Buttelli Ramos* \\ Lucas e Silva Batista Pilau**
}

SUMÁRIO: Introdução; 2 A Lei Federal $n .^{\circ}$ 12.654/2012 e a transnacionalização da doxa punitiva; 3 Governamentalidade penal, dispositivo e estado de exceção: assentando as coordenadas conceituais da crítica; 4 A Expansão do aparato punitivo estatal e os possíveis desdobramentos da Lei Federal $n .{ }^{\circ} 12.654 / 2012 ; 5$ Considerações finais; Referências.

RESUMO: Neste artigo os autores pretendem discutir, a partir da análise da Lei Federal n. ${ }^{\circ}$ 12.654/2012, de que maneira as inovações normativas concebidas com sua promulgação terminam inscrevendo no plano geral das estratégias da governamentalidade jurídico-penal um novo e decisivo dispositivo de segurança que detém, ao menos potencialmente, a capacidade de ressignificar a importância política do corpo encarcerado. Pela realização de extensa revisão bibliográfica e do emprego do método hipotético-dedutivo, os autores buscam esclarecer de que maneira os conceitos de "governamentalidade", "dispositivo de segurança" e "estado de exceção", podem contribuir para a ampliação da compreensão acerca das consequências biopolíticas que resultam da criação da hipótese de extração compulsória de material genético como uma das formas de identificação criminal disponíveis no âmbito do ordenamento jurídico brasileiro. A incorporação dos aludidos conceitos ao debate sobre a legitimidade da referida forma de identificação criminal sugere que a Lei Federal n. ${ }^{\circ}$ 12.654/2012 representa um verdadeiro "dispositivo de segurança", cuja operacionalização tem como efeito mais imediato a relegação do corpo encarcerado ao plano da exceção. Os autores concluem o estudo proposto afirmando que a manutenção dessa forma de identificação no ordenamento jurídico brasileiro representa grave risco à concepção do condenado como um sujeito de direitos.

PALAVRAS-CHAVE: Lei Federal n. ${ }^{0}$ 12.654/2012; Biopolítica; Dispositivos de segurança; Governamentalidade; Aparato político-estatal.

\footnotetext{
Mestre em Ciências Criminais pela Pontifícia Universidade Católica do Rio Grande do Sul (PUCRS), Brasil. E-mail: mbuttelliramos@hotmail.com

** Mestre em Ciências Criminais pela Pontifícia Universidade Católica do Rio Grande do Sul (PUCRS), Brasil
} 


\title{
DISCUSSING A NEW BIO-POLITICAL ASPECT OF THE IMPRISONED PERSON: CONTROVERSIES ON FEDERAL LAW $12.654 / 2012$
}

\begin{abstract}
The authors discuss the manner normative innovations conceived in the promulgation of Federal Law 12,654/2012 inscribe a new and decisive safety item within the general plan of juridical-penal strategies of governability, which holds, at least potentially, the capacity of re-signifying the political importance of the imprisoned person. Foregrounded on extensive bibliography and on the hypothetical and deductive method, the authors demonstrate how the concepts of 'governability', 'safety device' and 'state of exception' contribute towards the broadening of an understanding on the bio-political consequences that establish the hypothesis of compulsory extraction of genetic material as one of the methods for criminal identification available within Brazilian law. The incorporation of these concepts on the discussion on the legitimation of criminal identification suggests that Federal Law 12,654/2012 is a true 'safety device' transforming the imprisoned body into an exceptional state. Results show that this identification form within Brazilian law is a serious risk to the concept of the condemned person as a subject with rights.
\end{abstract}

KEY WORDS: Federal Law 12.654/2012; Bio-politics; Safety rules; Governability; Political and state apparatus.

\section{EXPLORANDO UNA NUEVA DIMENSIÓN BÍOPOLÍTICA DEL CUERPO ENCARCELADO: CONTROVERSIAS EN TORNO DE LA LEY FEDERAL N. ${ }^{\circ} 12.654 / 2012$}

RESUMEN: En este artículo los autores pretenden discutir, a partir del análisis de la Ley Federal $\mathrm{n}^{\mathrm{O}}$ 12.654/2012, de qué manera las innovaciones normativas concebidas con su promulgación terminan inscribiendo en el plan general de las estrategias de la gobernabilidad jurídico-penal un nuevo y decisivo dispositivo de seguridad que detiene, al menos potencialmente, la capacidad de resignificar la importancia política del cuerpo encarcelado. Por intermedio de la realización de extensa revisión bibliográfica y del empleo del método hipotético-deductivo, los autores buscan aclarar de qué manera los conceptos de "gobernabilidad", "dispositivo de seguridad" y "estado de excepción", puede contribuir a la ampliación de la comprensión acerca de las consecuencias biopolíticas que resultan de la creación de la hipótesis de extracción compulsoria de material genético como una de las formas de identificación criminal disponibles en el ámbito del ordenamiento jurídico brasileño. La incorporación de los aludidos conceptos a discusión sobre la legitimidad de la referida forma de identificación criminal sugiere que la Ley Federal n. ${ }^{\circ}$ 12.654/2012 
representa un verdadero "dispositivo de seguridad", cuya gestión tiene como efecto más inmediato la relegación del cuerpo encarcelado al plan de la excepción. Los autores concluyen el estudio propuesto afirmando que la manutención de esa forma de identificación en el ordenamiento jurídico brasileño representa grave riesgo a la concepción del condenado como un sujeto de derechos.

PALABRAS ClAVE: Ley Federal n. ${ }^{0}$ 12.654/2012; Biopolítica; Dispositivos de Seguridad; Gobernabilidad; Aparato Político-estatal.

\section{INTRODUÇÃO}

O presente trabalho assume como proposta realizar, por meio extensa revisão bibliográfica e do emprego do método hipotético-dedutivo, um exame crítico da Lei Federal n. ${ }^{\circ}$ 12.654/2012, a partir do entrelaçamento dos marcos teóricos criminológico e político-filosóficos, tudo a fim de suscitar o debate interdisciplinar acerca da legitimidade do dispositivo normativo que versa sobre a criação da hipótese de extração compulsória de material genético como forma de identificação criminal. Refere-se, com efeito, à norma inscrita no artigo $3^{\circ}$ lei federal em questão que cria o artigo 9-A no âmbito da Lei de Execução Penal (Lei Federal n. ${ }^{0}$ 7.210/84) e possibilita a coleta compulsória de material genético de indivíduos condenados pela prática de crime doloso, cometido com violência de natureza grave contra pessoa, ou qualquer outro crime considerado hediondo, nos termos da Lei Federal n. ${ }^{\circ}$ 8.072/90.

Destarte, buscando refúgio nas filosofias políticas de Michel Foucault e de Giorgio Agamben, procurar-se-á desenvolver um debate em torno de três hipóteses: (i) a Lei Federal n. ${ }^{\circ}$ 12.654/12 pode ser compreendida como um instrumento (jurídico) a serviço da governamentalidade biopolítica, já que permite ao Estado incorporar aos seus cálculos e estratégias de poder e segurança as mais elementares informações sobre a vida dos indivíduos mantidos sob a sua custódia; (ii) a mesma Lei Federal pode ainda ser pensada como uma espécie de dispositivo de segurança que subjuga e controla, em um sentido que se supõe útil à razão de Estado, a liberdade de certos indivíduos em relação à disposição do seu próprio corpo; (iii) a Lei Federal n. ${ }^{\circ}$ 12.654/12 instaurou, ainda, em relação a um certo conjunto de sujeitos, um verdadeiro regime de exceção em relação à fruição de direitos e garantias individuais fundamentais.

Sob o ponto de vista da reflexão criminológica, assumir-se-á a hipótese de 
que a excepcional modalidade de identificação criminal instituída pela Lei Federal n. ${ }^{\circ} 12.654 / 12$ pode, em razão das tendências expansionistas e punitivas da política criminal brasileira, se consolidar como uma regra não mais restrita aos condenados pela prática de crimes cometidos mediante o emprego de violência ou considerados hediondos.

O presente escrito foi dividido em três partes: na primeira apresenta-se a Lei Federal n. ${ }^{\circ}$ 12.654/12 e esclarece-se de que forma o debate em torno da sua aplicabilidade vem sendo desenvolvido pelos tribunais brasileiros, com especial ênfase na jurisprudência do Supremo Tribunal Federal. Alude-se, ainda, o fato de que o debate acerca da possibilidade de coleta de material genético para fins de identificação criminal, embora ainda incipiente no Brasil, possui longo retrospecto nos Estados Unidos da América e na Europa. A segunda parte dedica-se, com efeito, à explicitação do referencial teórico que embasa a problematização das hipóteses suscitadas. No ponto, elenca-se uma longa série de esclarecimentos acerca dos sentidos atribuídos aos conceitos de "governamentalidade biopolítica", "dispositivo" e "estado de exceção". Na terceira e última parte, perscruta-se a validade jurídica do permissivo instituído pela Lei Federal n. ${ }^{0}$ 12.654/12 à luz dos planos infraconstitucional, constitucional e convencional. Conclui-se o típico com a apresentação dos argumentos, de corte criminológico, que indicam a possibilidade do método de identificação concebido pela Lei Federal n. ${ }^{\circ}$ 12.654/12 se consolidar como uma regra aplicável a toda forma ou espécie de condenação. 


\section{A LEI FEDERAL N. ${ }^{\circ}$ 12.654/2012 E A TRANSNACIONALIZAÇÃO DA DOXA PUNITIVA}

Em 29 de maio do ano de 2012 foi promulgada a Lei Federal n. ${ }^{\circ} 12.654^{03}$. Entre as principais inovações constantes da Lei em comento figuram as coordenadas do processo de coleta de material genético para fins de identificação criminal. A propósito disso, vale proceder à transcrição do artigo $3^{\circ}$ do referido diploma normativo, que trata de criar permissivo legal até então sem precedente no âmbito ordenamento jurídico pátrio.

Art. $3^{\circ}$. A Lei n. ${ }^{\circ}$ 7.210, de 11 de julho de 1984 - Lei de Execução Penal, passa a vigorar acrescida do seguinte art. $9^{\circ}$-A: "Art. $9^{\circ}$-A. Os condenados por crime praticado, dolosamente, com violência de natureza grave contra pessoa, ou por qualquer dos crimes previstos no art. $1^{\circ}$ da Lei no 8.072, de 25 de julho de 1990, serão submetidos, obrigatoriamente, à identificação do perfil genético, mediante extração de DNA ácido desoxirribonucleico, por técnica adequada e indolor.

Ao introduzir nova regra no âmbito da normatividade da Lei de Execução Penal $^{04}$, a Lei Federal n. ${ }^{\circ}$ 12.654/2012 veio consagrar a hipótese da extração compulsória de material genético, como forma de identificação de criminal, de indivíduos condenados pela prática de crimes violentos ou considerados hediondos, nos termos da Lei Federal n. ${ }^{\circ} 8.072 / 1990^{05}$.

Da data da publicação da Lei Federal em questão até o presente momento verifica-se, pois, o transcurso de quase cinco anos sem que a validade do aludido permissivo legal tenha sido efetivamente apreciada em sede de controle concentrado

${ }^{03}$ BRASIL. Lei Federal n. ${ }^{\circ} 12.654$ de 28 de maio de 2012. Altera as Leis nos 12.037, de $1^{\circ}$ de outubro de 2009, e 7.210, de 11 de julho de 1984 - Lei de Execução Penal, para prever a coleta de perfil genético como forma de identificação criminal, e dá outras providências. Diário Oficial [da] República Federativa do Brasil, Brasília, DF, 29 maio de 2012.

${ }^{04}$ BRASIL. Lei Federal n. ${ }^{0} 7.210$ de 11 de julho de 1984. Institui a Lei de Execução Penal. Diário Oficial [da] República Federativa do Brasil, Brasília, DF, 13 jul. 1984.

${ }^{05}$ BRASIL. Lei Federal n. ${ }^{\circ} 8.072$ de 25 de julho de 1990. Dispõe sobre os crimes hediondos, nos termos do art. $5^{\circ}$, inciso XLIII, da Constituição Federal, e determina outras providências. Diário Oficial [da] República Federativa do Brasil, Brasília, DF, 26 jul. 1990. 
de constitucionalidade ${ }^{06}$. Com efeito, embora se possa encontrar na jurisprudência dos tribunais regionais precedentes que afastam a aplicação da lei ${ }^{07}$, mormente $o$ caráter compulsório da identificação referida pelo artigo 9-A da Lei de Execução Penal, a questão, per se, ainda pende de apreciação pelo plenário da Suprema Corte.

A dificuldade constatada em torno da definição de um posicionamento definitivo, por parte da Suprema Corte, acerca da constitucionalidade do referido diploma legal denota, ao menos em sede de hipótese, o atual estado de coisas que caracteriza a política criminal brasileira que, após décadas de ampliação e recrudescimento das estratégias de encarceramento, foi finalmente capaz de produzir lei de natureza infraconstitucional que, malgrado o seu patamar hierárquico, desafia abertamente limites preconizados pela Constituição Federal ${ }^{08}$ à atividade da persecução criminal.

Sem embargo, é de suma importância assinalar, desde já, que a Lei Federal n. ${ }^{\circ}$ 12.654/2012 não deriva, exclusivamente, de discussões travadas em solo brasileiro. Bem compreendidos os seus antecedentes históricos, a partir de uma análise de direito comparado, tem-se que o diploma legal em questão foi claramente inspirado por política probatória gestada e aprimorada pelos Estados Unidos da América, precursor no emprego desta metodologia de coleta de prova. Embora a coleta obrigatória de material biológico para fins de constituição de bancos de dados de perfis genéticos seja amplamente defendida, mormente por técnicos e gestores da área da

\footnotetext{
${ }^{06}$ Até a data da submissão deste artigo pendia de julgamento, no âmbito do Supremo Tribunal Federal, o Recurso Extraordinário n ${ }^{\circ}$ 973837/MG. Atualmente sob a relatoria do Min. Gilmar Mendes, o recurso em comento, interposto pelo Defensor Público-Geral do estado de Minas Gerais, persegue, fundamentalmente, a declaração de inconstitucionalidade do artigo 9-A da Lei de Execução Penal, derivado da Lei Federal n. ${ }^{\circ}$ 12.654/2012, sob a alegação de que a submissão obrigatória do condenado à coleta de material genético, mediante extração de Ácido Desoxirribonucleico (DNA), viola, a um só tempo, o direito fundamental à intimidade e a garantia constitucional que veda a imposição de obrigações que gerem a possibilidade de autoincriminação. BRASIL. Supremo Tribunal Federal (Tribunal Pleno). Repercussão Geral no Recurso Extraordinário n. ${ }^{\circ}$ 973837. Relator: Ministro Gilmar Mendes. Brasília, 11 de outubro de 2016. Acesso em: 15 de nov. 2016.

${ }^{07}$ BRASIL. Supremo Tribunal Federal (Segunda Turma). Reclamação n. ${ }^{\circ}$ 19.843. Relator: Ministro Celso de Mello. Brasília, 25 de jun. 2015. BRASIL. Supremo Tribunal Federal (Primeira Turma). Reclamação n. ${ }^{\circ} 19.208$. Relator: Ministro Luiz Fux. Brasília, 9 de set. 2015; BRASIL. Supremo Tribunal Federal (Segunda Turma). Reclamação n. ${ }^{\circ}$ 20.950. Relatora: Ministra Cármen Lúcia. Brasília, 25 de out. 2015.

${ }^{08}$ BRASIL. Constituição (1988). Constituição da República Federativa do Brasil. Brasília, DF: Senado Federal: Centro Gráfico, 1988. 292 p.
} 
segurança pública ${ }^{09}$, o expediente em si, sobretudo nos casos em que a extração de material se dá de maneira compulsória, tem sido alvo de inúmeras objeções. Como bem observa por Maria Elizabeth Queijo, recentes pesquisas conduzidas no Reino Unido $^{10}$ demonstram que o conteúdo das informações armazenadas pelos bancos de dados em comento é inequivocamente influenciado pela dinâmica seletiva que caracteriza, em larga medida, o funcionamento das instâncias oficiais de repressão que compõem os sistemas contemporâneos de justiça criminal ${ }^{11}$ :

[...] os negros são alvo mais frequente de detenções do que os brancos e acabam tendo seu material genético registrado nos bancos de dados, o que potencializa, sobremaneira, suas chances de condenação criminal em relação aos brancos ${ }^{12}$.

Não obstante tais apontamentos, o que efetivamente se pretende ressaltar, neste artigo, é que a hipótese de que a vigência mesma do artigo 9-A da Lei de Execuções Penais, concebido pela Lei Federal n. ${ }^{0}$ 12.654/2012, revela, aparentemente, uma espécie de déficit crítico do discurso jurídico que, por si só, não tem sido capaz de dar conta dos problemas filosóficos e políticos que resultam do desenvolvimento "pari passu" das biotecnologias e deste fenômeno social contemporâneo descrito por Denis Salas sob o epíteto da vontade de punir. Para Salas, o fenômeno da vontade de punir tem a ver com a própria ressignificação histórica pela qual passa a ideia mesma do poder de punir. Para o magistrado francês, as sociedades contemporâneas, cada vez mais confrontadas com o sentimento de insegurança, passam a exigir do Estado mais acusações, mais julgamentos e, consequentemente, mais condenações. Essa demanda crescente por punição aporta, preferencialmente,

\footnotetext{
${ }_{09}$ SCHIOCCHET observa que a crescente utilização de biotecnologias na seara da persecução criminal se deve, em larga medida, à sedimentação, entre os operadores do Direito, da crença de que a racionalidade científica que embasa a genética viabilizaria, quando aplicada ao processo penal, a formulação de juízos probatórios absolutamente precisos, dotados, pois, de certeza matemática (SCHIOCCHET, Taysa. O humano entre o direito a e genética: pressupostos para o debate legislativo acerca das implicações jurídicas concernentes à criação de bancos de perfis genéticos para fins de persecução criminal. In: CALLEGARI, André Luis et al. (Org.). Constituição, sistemas sociais e hermenêutica: Anuário do PPG em Direito da Unisinos - Mestrado e Doutorado. $1^{\mathrm{a}}$ ed. Porto Alegre: Livraria do Advogado, 2011, v. 8, p. 300).

${ }^{10}$ Primeiro país a instituir um biobanco para fins de persecução criminal (Idem, p. 300).

${ }^{11}$ A propósito da crítica à atuação seletiva dos atores institucionais incumbidos da atividade de persecução criminal, consultar, por todos, Alessandro Baratta, sobretudo o capítulo XII da obra em questão, intitulado "Do 'Labeling approach' a uma criminológica crítica" em: BARATTA, Alessandro. Criminologia Crítica e Crítica do Direito Penal. Trad. Juarez Cirino dos Santos. $3^{\mathrm{a}}$ ed. Rio de Janeiro: Revan: Instituto Carioca de Criminologia, 2002.

${ }^{12}$ QUEIJO, Maria Elizabeth. O princípio nemo tenetur se detegere e a coleta de material genético: identificação criminal ou colaboração na produção da prova?. In. Boletim Instituto Brasileiro de Ciências Criminais. Ano $21-$ n. ${ }^{\circ} 250$; Setembro/2013, p. 8.
} 
nos parlamentos que, no entendimento do autor, abdicaram do papel de controle dos influxos incriminadores oriundos da sociedade civil para funcionar como uma espécie de caixa de ressonância cujo propósito é, no limite, dar vazão aos anseios manifestados por grupos de pressão que, por sua vez, são colocados em permanente estado de excitação por um cerrado e incessante bombardeio midiático ${ }^{13}$.

Por essa razão, a análise da inovação jurídica engendrada pelo artigo 9-A da Lei de Execuções Penais partirá, no contrafluxo da técnica jurídica, de alguns "insigths" oriundos tanto da filosofia de Michel Foucault e Giorgio Agamben, como da teoria política de Chantal Mouffe e Carl Schmitt.

\section{GOVERNAMENTALIDADE PENAL, DISPOSITIVO E ESTADO DE EXCEÇÃO: ASSENTANDO AS COORDENADAS CONCEITUAIS DA CRÍTICA}

A leitura e análise dos problemas suscitados pelo advento da Lei Federal n. ${ }^{\circ} 12.654$ perpassa pelo domínio de um léxico composto por expressões típicas da filosofia política contemporânea, tais como dispositivo, estado de exceção e governamentalidade biopolítica. Neste sentido, considerando a intensa disputa existente em torno da definição do sentido destes significantes, convém precisar, a seguir, o sentido atribuído a cada uma das aludidas categorias no âmbito da presente análise. Importante esclarecer, contudo, que as categorias em questão são tipicamente polissêmicas. Veja-se, a propósito disso, o que ocorre com o conceito de dispositivo, que, nos atuais debates da filosofia política, encontra ao menos três acepções distintas, oriundas tanto obras de Foucault, Deleuze e Agamben. O mesmo sucede com o conceito de estado de exceção, originalmente teorizado por Schmitt e contemporaneamente problematizado por Agamben. Ambos os exemplos ilustram, pois, a necessidade de se dispensar especial atenção à semântica das categorias empregadas.

Feito esse registro, convém agora indicar que mesmo confrontados com um manancial de significações possíveis, optamos por aqueles sentidos que - pelas razões que serão mais detalhadamente elucidadas nos próximos tópicos-permitiram a problematização dessa hipótese que, em relação à questão da compulsoriedade da coleta de material biológico para fins de identificação criminal, nos parece central:

\footnotetext{
13 SALAS, Denis. La Voluntè de Punir: Essai sur le Populisme Pénal. Paris: Hachette, 2005, p. 14.
} 
o advento da Lei Federal n. ${ }^{\circ}$ 12.654/2012 representa, em termos politico-criminais, a institucionalização de um discurso baseado claramente na lógica (biopolítica) da exceção, uma lógica pautada, fundamentalmente, pela ideia da possibilidade de excepcionalização de certas garantias constitucionais em determinados contextos e em relação a determinados indivíduos. Iniciemos a discussão proposta pela revisão conceitual da categoria governamentalidade biopolítica.

Para Michel Foucault, a partir do século XVI, a preocupação com o estabelecimento de um fundamento (político) de legitimidade para o exercício do poder soberano ${ }^{14}$ foi sendo substituída por um conjunto de saberes cuja finalidade consistia na revelação dos aspectos básicos da arte de governar, sobretudo a partir da descoberta das regras e dos princípios gerais do como se governar, como ser governado e, finalmente, "como fazer para ser o melhor governante possível"15.

Esse processo histórico, que se inicia no século XVI e que encontra o seu apogeu no início do século XVIII, fomentou, no entendimento de Foucault, a realização de um giro axial nas prioridades do soberano, fazendo emergir, durante este interstício, uma economia política inteiramente nova ${ }^{16}$. A novidade inerente a essa nova forma de organização dos discursos sobre o poder na modernidade diz respeito - novamente partindo do entendimento assentado por Foucault - ao descobrimento, pelo Estado, da potencialidade política que se encerra na ideia de governo da vida humana, da vida da população que, associada à noção de território, foi guindada à condição de recurso natural cuja possibilidade de manutenção e reprodução estaria diretamente relacionada à qualidade e à eficiência dos processos disciplinares de controle da vida social ${ }^{17}$.

\footnotetext{
${ }_{14}$ Algo que, por todos, pode ser claramente conferido em HOBBES, Thomas. Leviatã, ou Matéria, Forma e Poder de um Estado Eclesiástico e Civil. Trad. Rosina D’Angina. $1^{\mathrm{a}}$ ed. São Paulo: Martin Claret, 2014.

${ }^{15}$ FOUCAULT, Michel. A governamentalidade. In Microfísica do Poder (1979), organização e tradução de Roberto Machado, Rio de Janeiro: Edições Graal, 2012, p. 277-278.

${ }^{16}$ Convém esclarecer, aqui, que o significado de economia, tal como trabalhado por Foucault, não se confunde com o significado comumente atribuído ao termo, que representa, hoje, uma disciplina, um conjunto organizado de saberes e discursos sobre a produção, distribuição e consumo de bens e serviços. Genealogicamente falando, o termo economia, derivado da expressão grega "oikonomia", originalmente dizia respeito ao governo da família, a gestão dos "indivíduos, dos bens e das riquezas no interior da família". A essa lógica de gestão da vida privada, a partir do século XVI, foi guindada ao plano macropolítico da administração estatal. A propósito disso, explica Foucault: "governar um Estado significará, portanto, estabelecer a economia ao nível geral do Estado, isto é, ter em relação aos habitantes, às riquezas, aos comportamentos individuais e coletivos, uma forma de vigilância, de controle tão atenta quanto à do pai de família" (FOUCAULT, Michel. A governamentalidade. Op. Cit., p. 281).

${ }^{17}$ Este processo foi detalhadamente retrado por Foucault em "Segurança, Território, População", sobretudo na aula ministrada no dia 18 de janeiro de 1978, oportunidade na qual autor propôs analisar as práticas disciplinares engendradas, no século XVIII, p. 59).
} 
Diferentemente do que ocorria durante o regime da soberania absoluta que, alheio ao princípio da identidade democrática ${ }^{18}$, jamais precisou esboçar qualquer sorte de preocupação com relação ao desenvolvimento de instituições e discursos voltados ao cuidado da vida dos governados, os Estados modernos puseram-se a pensar, em tempo integral, em novas tecnologias e saberes que cultivassem a potência produtiva inerente à vida humana, que passava então a ser compreendida como um bem político indispensável à manutenção do próprio Estado, algo impensável - vale recordar - para o Príncipe de Maquiavel ${ }^{19}$, o soberano dos Estados pré-modernos, para quem a figura do súdito era, no mínimo, dispensável, ou como diria Giorgio Agamben, "matável". Desde então, a vida dos indivíduos, antes relegada a um espaço de diminuta importância política, passou a ser considerada "como um dado, como um campo de intervenção (e legitimação política)" ${ }^{\text {20 }}$, como um espaço privilegiado de desenvolvimento, teste e aprimoramento de técnicas de governo.

Feito o registro dessas considerações iniciais, podemos, finalmente, indicar o sentidoapartirdoqualcaptamosaideiadegovernamentalidadebiopolítica. Trata-se, pois (i) de um conjunto não determinável "a priori" de "instituições, procedimentos, análises e reflexões" ${ }^{21}$, que tem por objeto a promoção da vida biológica da população a partir daquilo que Foucault denominou de dispositivos de segurança; (ii) de um novo paradigma de controle social baseado na adoção de políticas públicas dedicadas ao desenvolvimento das potencialidades produtivas do ser humano; (iii) do cume mais alto de um processo histórico caracterizado pela superação dos modelos feudal e administrativo pelo Estado de governo, cujo mote é, justamente, o aprimoramento contínuo de saberes e práticas institucionais destinadas à potencialização das competências produtivas da população (do) no território governado ${ }^{22}$.

Tendo em vista esses três traços característicos, pode-se dizer que os governos modernos, ao esboçar as suas estratégias em torno da segurança da população, levam em consideração, ao menos, duas questões: (i) a primeira diz respeito à delimitação dos perigos que ameaçam a vida da população, isto é, à identificação dos sujeitos e

\footnotetext{
18 De acordo com este princípio, analisado, dentre outros, pela politóloga belga Chantal Mouffe, um dos fundamentos políticos da soberania moderna repousa na possibilidade de se identificar uma relação de simetria entre a identidade do governante e a identidade dos governados.

${ }^{19}$ Cuja existência, ensinava Foucault, baseava-se no seguinte princípio: "o príncipe está em relação de singularidade, de exterioridade, de transcendência em relação ao seu principado" (FOUCAULT, Michel. A governamentalidade. In Microfísica do Poder (1979), organização e tradução de Roberto Machado, Rio de Janeiro: Edições Graal, 2012, p. 279).

${ }^{20}$ Idem

21 Idem.

22 Idem.
} 
práticas sociais que colocam em xeque a "saúde" do corpo social; (ii) a segunda, por sua vez, concerne ao desenvolvimento de estratégias e táticas que têm por finalidade a manipulação das relações de força que se desenvolvem no interior do território governado, subordinando-as, com efeito, a uma razão de Estado, ou seja, a interesses de natureza preponderantemente burocrática ${ }^{23}$.

Possível perceber, destarte, que o estudo da governamentalidade biopolítica ganha importância na medida em que permite analisar a razão que inspira o modo de funcionamento dos dispositivos de segurança, que, diferentemente dos estáticos dispositivos disciplinares de outrora, servem para naturalizar e ampliar o governo da vida dos homens ${ }^{24}$.

A Lei Federal n. ${ }^{\circ}$ 12.654/2012 se inscreve na discussão foucaultiana com perfeição, uma vez que a pretexto de melhor organizar a economia dos processos de investigação dos crimes no Brasil, institui um banco de dados composto, basicamente, por "material genético desviante", cujo acúmulo e gestão garantem poder revelar a identidade dos inimigos que atentam contra a ordem jurídica estabelecida e, consequentemente, contra os interesses da comunidade não desviante.

Em atenção ao discurso que figura na justificativa adotada para a edição da Lei em comento, pode-se dizer que mais a destacada pretensão do diploma legal em questão é, justamente, garantir a segurança da população, reduzindo, por meio do emprego em larga escala de uma técnica científica dotada de uma aparentemente incontestável precisão, os perigos que derivam das incertezas típicas que caracterizam o processo de descoberta da "identidade criminosa".

Antes de avançarmos em direção à questão do estado de exceção, convém nos determos por um instante na análise do conceito de dispositivo, cuja compreensão é de capital importância para que se possa entender a potência e as consequências políticas engendradas pelas reformas instituídas pelo diploma legal em comento, mais especificamente pelo seu art. $3^{\circ}$, que acresce à redação do art. $9^{\circ}$ da Lei Federal n. ${ }^{0}$ 7.210/90 (Lei de Execução Penal) norma que passa a impor a determinados indivíduos a obrigação de fornecer ao Estado material biológico sob o pretexto de constituição de um banco de dados genético a ser consultado para fins de identificação criminal.

Tendo a obra de Michel Foucault como ponto de partida, o filósofo

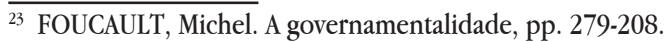

${ }^{24}$ FOUCAULT, Michel. Segurança, Território e População. Curso do Còllege de France (1977-1978); São Paulo: Martins Fontes, 2008, p. 158. 
italiano Sandro Chignola identifica duas interpretações para a utilização do termo dispositivo ${ }^{25}$. Uma primeira advinda do pensamento de Giorgio Agamben ${ }^{26}$ e outra oriunda das reflexões de Judith Revel ${ }^{27}$. Conforme o entendimento preconizado por Chignola ${ }^{28}$, a noção defendida por Agamben parte da pressuposição de que o conceito foucaultiano de dispositivo deriva diretamente da noção de positividade, tal como foi preconizada por Jean Hyppolite. De acordo com Agamben, Hyppolite teria, ao analisar a obra de Hegel, extraída a noção de positividade da noção de "religião positiva". Tal noção compreenderia, com efeito, o conjunto de crenças, de regras e ritos que em determinada sociedade e momento histórico seriam impostos aos indivíduos pelo exterior. Seriam, pois, essas crenças, regras e ritos os dispositivos vocacionados à regulação da vida humana. Tornaremos a discutir a noção agambeniana, em seguida, tomando por base, agora, as ideias preconizadas pelo próprio autor no ensaio "O que é dispositivo?".

Outra dimensão conceitual teria sido apresentada por Judith Revel. Para a autora, noção de dispositivo, em Foucault, seria, na realidade, fruto da mudança intentada pelo autor em relação ao foco das suas pesquisas. Nesse sentido, se antes o conceito de dispositivo, ainda pautado pela perspectiva da arqueologia dos saberes, designava o campo epistemológico (epistéme) que permitia detectar as simultaneidades e as diferenças entre os saberes, mais tardiamente, mais precisamente a partir da assunção da perspectiva da genealogia dos poderes, a noção passa a ser entendida como todo elemento capaz de dar vazão aos poderes pautados por saberes que agem de forma articulada objetivando a ordenação dos limites do possível relativamente ao exercício das liberdades individuais ${ }^{29}$.

${ }^{25}$ CHIGNOLA, Sandro. Sobre o dispositivo: Foucault, Agamben, Deleuze. Tradução de Sandra Dall Onder. Cadernos IHU Ideias. Instituto Humanitas Unisinos. Ano 12, n. ${ }^{\circ}$ 214, vol. 12. São Leopoldo, Universidade do Vale do Rio dos Sinos, 2014.

${ }^{26}$ AGAMBEN, Giorgio. O que é o dispositivo? In O que é o contemporâneo e outros ensaios. Trad. Vinícius Nicastro Honesko. Chapecó: Santa Catarina: Argos, 2009, p. 25-54.

${ }^{27}$ REVEL, Judith. Michel Foucault: conceitos essenciais. Tradução Maria do Rosário Gregolin, Nilton Milanez, Carlos Piovesani. São Carlos: Claraluz, 2005.

${ }^{28}$ CHIGNOLA, Sandro. Sobre o dispositivo: Foucault, Agamben, Deleuze. Tradução de Sandra Dall Onder. Cadernos IHU Ideias. Instituto Humanitas Unisinos. Ano 12, n. ${ }^{\circ}$ 214, vol. 12. São Leopoldo, Universidade do Vale do Rio dos Sinos, 2014.

${ }^{29}$ REVEL, Judith. Michel Foucault: conceitos essenciais. Tradução Maria do Rosário Gregolin, Nilton Milanez, Carlos Piovesani. São Carlos: Claraluz, 2005, p. 40. 
Além do próprio Foucault ${ }^{30}$, Gilles Deleuze e Giorgio Agamben, em ocasiões distintas, também propuseram discutir, à luz dos tempos contemporâneos, o significado do conceito de dispositivo. Embora tenham chegado a conclusões relativamente distintas, ambos os autores partem de uma mesma premissa: compreender o que define, em última instância, o propósito analítico dessa noção que costuma ser definida - muito genericamente - como uma espécie de elemento amorfo que organiza, no plano da microfísica, as estratégias de governamentalidade biopolítica da vida humana.

Para Deleuze, o dispositivo foucaultiano, analisado a partir da figura da rede foucaultiana, representa, a um só tempo, um ponto nodal, um elo de convergência, um nó de articulação, um local a partir do qual se estabelece toda uma complexa relação de práticas e discursos constituídos por linhas argumentativas heterogêneas, multiformes e pluridimensionais. O dispositivo, de acordo com a leitura deleuziana, é, por assim dizer, aquilo que deixa falar e ver, aquilo que, ao mesmo tempo, impede de ver e dizer, aquilo que forma, por meio de linhas de estratificação ou sedimentação, desconstrói, por meio de linhas de desestruturação, e reconstrói, por meio de linhas de atualização, a subjetividade humana ${ }^{31}$.

A tarefa de subjetivação e controle da vida humana operada pelos dispositivos também foi analisada por Giorgio Agamben, que define o conceito não apenas como uma tecnologia específica do poder, mas, também, como um termo geral que ilustra a crítica realizada por Michel Foucault às "categorias universais", assim compreendidas todas as manifestações do pensamento que ilustram tipos de razões totalizantes, a saber, o Estado, a Soberania, a Lei, o Poder etc.. É que para Foucault, importante recordar, nenhuma dessas categorias era ou poderia ser determinada a priori, senão que cada uma delas era definida, em seu sentido, pelos dispositivos que as traduziam, contextualmente, sempre a partir de uma intricada e constante relação de interação e (re)significação.

Agamben, contudo, distancia-se da perspectiva foucaultiana e da descrição deleuziana do dispositivo na medida em que procura refletir sobre a raiz terminológica

\footnotetext{
${ }^{30}$ Em entrevista à International Psychoanalytical Association (IPA), Foucault esboça um conceito de dispositivo ao referir que a noção representa "um conjunto decididamente heterogêneo que engloba discursos, instituições, organizações arquitetônicas, decisões regulamentares, leis, medidas administrativas, enunciados científicos, proposições filosóficas, morais, filantrópicas. Em suma, o dito e o não dito são os elementos do dispositivo. O dispositivo é a rede que se pode tecer entre estes elementos" (FOUCAULT, Michel. Sobre a história da sexualidade. In Microfísica do poder. Trad. Roberto Machado. Rio de Janeiro: Graal, 2012, p. 244).

31 DELEUZE, Gilles. Que és un dispositivo? In BALIBAR, Etinenne; DREYFUS, Hubert; DELEUZE, Gilles et al. Michel Foucault, filósofo. Barcelona: Gedisa, 1999, p. 161.
} 
da expressão a partir da teologia cristã. Para um aprofundamento dessa questão, estritamente necessária se faz a leitura do próprio escrito agambeniano ${ }^{32}$. Por ora, basta referir, em atenção aos propósitos deste escrito, que a noção de oikonomia emerge no circuito intelectual do ocidente pré-moderno a partir da expressão dispositio, tradução atribuída à expressão grega por padres latinos. Essa constatação torna-se relevante na medida em que aponta, de forma segura, para o sentido histórico acoplado à noção. Veja-se, portanto, que o conceito de dispositivo assume "em si toda a complexa esfera semântica da 'oikonomia' teleológica"33.

Após a identificação desse importante antecedente histórico, Agamben sugere a necessidade de se abdicar, ao menos momentaneamente, da filologia foucaultiana para pensar o conceito a partir de uma nova perspectiva. Essa nova perspectiva, por sua vez, diz respeito a uma imagem mental que divide o campo social em dois polos, situando, de um lado, os seres viventes, e, de outro, os dispositivos. Segundo Agamben, as subjetividades emergem como resultado final do processo de subjetivação que se inicia com a captura dos sentidos do homem pelos dispositivos, e que culmina na formação de corpos dóceis, disciplinados. Até aqui não existem, de fato, grandes novidades na proposta agambeniana de (re)leitura do conceito de dispositivo, afinal, tal interpretação foi consagrada pelos próprios escritos de Michel Foucault.

A especificidade, e, por conseguinte, a relevância teórica, da análise intentada pelo filósofo italiano reside num outro ponto: para Agamben, a análise dos dispositivos deve transcender a simples descrição dos processos de subjetivação por eles engendrados; com efeito, na atualidade, o campo de investigação retratado pelo conceito deve abrir espaço para a descoberta e consequente problematização dos "novos dispositivos", já que eles - muito em função da consolidação dos valores capitalistas - proliferam nas sociedades contemporâneas, não mais se limitando àquelas instituições totais (p. ex. as prisões, os manicômios, as escolas, a família, os hospitais etc.) cujo funcionamento foi debatido e criticado, sobretudo por Foucault, e cuja relação com os aparatos institucionais e saberes voltados à dominação dos homens sempre foi mais ou menos evidente.

Seguindo as pistas deixadas por Agamben, tende-se a reconhecer a importância do estudo de um conjunto menos óbvio de dispositivos que refletem

${ }_{32}$ AGAMBEN, Giorgio. O que é o dispositivo? In: O que é o contemporâneo e outros ensaios. Trad. Vinícius Nicastro Honesko. Chapecó: Santa Catarina: Argos, 2009, p. 25-54.

33 Idem, p. 38. 
certos signos culturais que, embora já naturalizados pelo homem moderno, não deixam de funcionar como verdadeiros moduladores da persona humana contemporânea. A fim de tornar mais clara essa nova compreensão que se assenta em torno do conceito de dispositivo, vale transcrever in totum passagem presente no ensaio agambeniano.

Generalizando posteriormente a já amplíssima classe dos dispositivos foucaultianos, chamarei literalmente de dispositivo qualquer coisa que tenha de algum modo a capacidade de capturar, orientar, determinar, interceptar, modelar, controlar e assegurar os gestos, as condutas, as opiniões e os discursos dos seres viventes ${ }^{34}$.

Destarte, ao aderir ao conceito preconizado por Agamben, compreende-se que a noção mais frutífera, sob o ponto de vista analítico, de dispositivo lhe apresenta como sendo tudo aquilo que é capaz de controlar e orientar, em um sentido que se supõem útil, os comportamentos e pensamentos dos homens. Essa abordagem conceitual, inovadora em muitos aspectos, permite pensar as circunstâncias nas quais a linguagem passa a funcionar, ela própria, como um dispositivo de controle. A amplíssima dimensão semântica defendida pelo aludido filósofo autoriza, com efeito, refletir acerca das modulações de sentido pelas quais passa a gramática legal para poder ampliar ou reduzir o campo da decidibilidade política sobre questões que antes se compreendiam reguladas, com aparentemente exclusividade, pela esfera jurídica. Ao incorporar essas perspectivas pode-se, finalmente, avançar em direção à questão do Estado de exceção.

A obra do jurista Carl Schmitt desperta, há décadas, o interesse da comunidade científica, sobretudo dos investigadores que se situam no campo da ciência política. Dentre os autores que se ocuparam da análise da obra do hostilizado jusfilósofo alemão, despontam a politóloga belga Chantal Mouffe (2000) e, uma vez mais, o filósofo Giorgio Agamben (2014).

Diferentemente de Mouffe, que busca compreender a essência das disputas políticas pelo poder no âmbito das sociedades democráticas a partir do estuda dinâmica relacional encarnada pela díade schmmitiana: amigo versus inimigo, Agamben resgata a obra de Schmitt com o intuito de pensar as formas e os fundamentos de legitimidade invocados pelo poder soberano nos Estados 
contemporâneos $^{35}$. O estudo perfectibilizado por Agamben - claramente inspirado no método genealógico foucaultiano - fornece uma ampla e precisa explicação acerca da dinâmica que orienta o funcionamento do Estado de exceção ao contrapor a teoria da soberania preconizada por Schmitt, sobretudo na obra "Teologia Política"36, à teoria da violência pura, formulada por Walter Benjamin em "Crítica da violência: crítica ao poder" ${ }^{37}$. Para Agamben, o significado do termo Estado de exceção pode ser depreendido da análise do verdadeiro "dossiê esotérico" resultante do embate teórico havido entre esses dois autores.

A interessante abordagem apresentada por Agamben demonstra, em síntese, como o trabalho de Schmitt representa, acima de tudo, uma resposta ao ensaio subscrito por Benjamin, que, por sua vez, busca pensar a possibilidade de uma violência revolucionária (ou divina, como queria o autor), que se situa "fora" e, portanto, para "além" do ordenamento jurídico, ou seja, uma violência que não funda e nem preserva o direito, mas que visa, simplesmente, a sua deposição, não sendo ela própria, por definição, capturável pelo léxico jurídico. Contrapondo os argumentos benjaminianos, Schmitt afirma ser impossível existir uma violência tal como aquela apresentada por Benjamin, posto que a anomia não pode, sob qualquer perspectiva, escapar ao direito, uma vez que ela nele se inscreve por meio da sua própria negação. Nestes termos, Schmitt busca neutralizar a energia subversiva da violência pura benjaminiana ao inscrevê-la no próprio ordenamento jurídico, concebendo, destarte, uma violência equivalente: a violência soberana, que diz respeito ao poder de decisão do soberano - contemporaneamente encarnada no Estado - de suspender, por meio da declaração da exceção, a aplicabilidade do direito, mantendo, contudo, a sua vigência, tudo com vistas à preservação da ordem jurídica. Eis o sentido sobre o qual o presente trabalho se deterá de agora em diante.

\footnotetext{
35 MOUFFE, Chantal. The Democratic Paradox. Verso: London, 2000, p. 49.

${ }^{36}$ SCHMITT, Carl. "Teologia Política". In: A crise da democracia parlamentar. Trad. Inês Lohbauer. São Paulo: Scritta, 1996.

${ }^{37}$ BENJAMIN, Walter. Para uma crítica da violência. In Escritos sobre mito e linguagem (1915-1921). Trad. Susana Kampff e Ernani Chaves. São Paulo: Editora 34, 2011.
} 


\section{LEI FEDERAL N. ${ }^{\circ}$ 12.654/2012 E CONTROLE DE CONSTITUCIONALIDADE: NOTAS SOBRE A EXPANSÃO DO PODER PUNITIVO}

Como dito no início deste artigo, ao instituir a possibilidade de coleta compulsória de material genético, a Lei Federal n. ${ }^{0}$ 12.654/12 tem violado, direta ou indiretamente, mas sempre sistematicamente, uma série de previsões legais oriundas tanto das ordens infraconstitucional e constitucional como do plano da convencionalidade. Mas quais direitos se encontram excepcionalmente em estado de suspensão? É o que se procurará verificar a seguir.

No plano da infraconstitucionalidade, a Lei Federal n. ${ }^{0}$ 12.654/12 choca-se, frontalmente, com a previsão normativa disposta pelo art. $3^{\circ}$ da Lei de Execuções Penais (LEP), onde se lê que ao condenado e ao internado "serão assegurados todos os direitos não atingidos pela sentença ou pela Lei”. Como se sabe, a sentença penal condenatória, para além das penas acessórias previstas nos artigos 91 e 92 do Código Penal, impinge, como regra, uma restrição apenas momentânea sobre a liberdade de locomoção do indivíduo. A Lei Federal n. ${ }^{\circ}$ 12.654/12, contudo, inaugura uma nova espécie de sanção, que constrange, agora, a capacidade dos condenados de dispor livremente sobre o seu próprio corpo, um direito que lhes é assegurado, convém salientar, pelo próprio art. $5^{\circ}$ da Constituição Federal.

$\mathrm{O}$ permissivo inscrito no art. $3^{\circ}$ da Lei n. $^{\circ} 12.654 / 12$ ainda fere de morte $o$ comando normativo que emana do art. 40 da Lei de Execução Penal, que institui, em relação às autoridades públicas que atuam na fase da execução penal, a obrigação de "respeito à integridade física e moral dos condenados e dos presos provisórios" ${ }^{38}$. Novamente, se considerarmos a inexistência no plano jurídico interno de regra capaz de autorizar aquilo que preconiza a Lei Federal n. ${ }^{0}$ 12.654/12, urge concluir que toda e qualquer violação do corpo do apenado (ou internado), ainda que mediante o emprego de "técnica adequada e indolor"39, consubstancia, muito simplesmente, um ato ilegal.

No que concerne ao plano da constitucionalidade, podemos, sem a pretensão de esgotar a crítica ou catalogar todas as hipóteses de violações possíveis, elencar as seguintes: (i) a coleta obrigatória de material genético relativiza, em prol

\footnotetext{
$\overline{{ }^{38}}$ BRASIL. Lei Federal $^{0}{ }^{0} 7.210$ de 11 de julho de 1984. Institui a Lei de Execução Penal. Publicada no Diário Oficial da União em 13 de julho de 1984.

39 BRASIL. Lei Federal n. ${ }^{\circ} 12.654$ de 28 de maio de 2012. Altera as Leis 12.037 , de $1^{\circ}$ de outubro de 2009, e 7.210, de 11 de julho de 1984 - Lei de Execução Penal, para prever a coleta de perfil genético como forma de identificação criminal, e dá outras providências. Publicada no Diário Oficial da União em 29 de maio de 2012.
} 
de uma retórica baseada no (pseudo)princípio constitucional da segurança pública, a força do postulado jurídico expresso pelo brocardo latino do nemo tenetur se detegere, também conhecido como a garantia gravada no inciso LXIII do artigo $5^{\circ}$ da Constituição Federal ${ }^{40}$, que veda a autoincriminação. É que o material genético colhido e armazenado pelas autoridades de que trata a lei federal em questão tem por finidade auxiliar o estado no exercício das atividades de investigação criminal, circunstância que determina, numa análise prospectiva, um potencial prejuízo para a defesa criminal daquele que fornece o seu próprio material genético; (ii) para além disso, a garantia constitucional atinente à inviolabilidade do direito à intimidade, também positivada na Constituição Federal (art. 50, "caput", e art. $5^{\circ}$ inc. $\mathrm{X}$, respectivamente), antagoniza, de igual forma, com a autorização expressa pelo art. $3^{\circ}$ da Lei Federal n. ${ }^{\circ}$ 12.654/12.

No plano da convencionalidade, é assaz oportuno ler as normas engendradas pela Lei n. ${ }^{0}$ 12.654/12 à luz da normatividade da Convenção Americana de Direitos Humanos (CADH), ratificada pelo Brasil por meio do Decreto n. ${ }^{\circ}$ 678/92. Com efeito, a garantia judicial referente à vedação à autoincriminação aparece contemplada, no aludido diploma internacional, no bojo do art. $8^{\circ}$, item 2, alínea "g" ${ }^{41}$. A garantia de inviolabilidade do direito à intimidade, por sua vez, vem consagrada no item 2 do art. 11 da referida Convenção.

Numa análise que, como dito, não se pretende definitiva, foram identificados, ao menos, seis fundamentos que inviabilizam, sob o ponto de vista legal, o exercício da atividade de identificação compulsória preconizada pela Lei Federal n. ${ }^{0}$ 12.654/12. Essa constatação apenas reforça a hipótese que sugere que a norma estatuída pelo artigo $3^{\circ}$ funciona, de fato, como um dispositivo, no sentido agambeniano, que opera a partir da lógica de exceção schmittiana, suspendendo o direito vigente, sob o pretexto de assegurar-lhe, senão a existência, então a própria autoridade.

Ainda, a propósito do caráter excepcional da autorização para coleta compulsória de material biológico, também seria preciso notar que nem perante um cenário de aguda instabilidade política a Constituição Federal chancela aquilo que a Lei Federal n. ${ }^{0}$ 12.654/12 tornou regra. Basta ver, com efeito, que essa

\footnotetext{
40 BRASIL. Constituição (1988). Constituição da República Federativa do Brasil. Brasília, DF: Senado Federal: Centro Gráfico, 1988. 292 p.

${ }^{41}$ Decreto n. ${ }^{\circ} 678$ de 6 de novembro de 1992. Promulga a Convenção Americana sobre Direitos Humanos (Pacto de São José da Costa Rica), de 22 de novembro de 1969. Publicado no Diário Oficial da União em 9 de novembro de 1992.
} 
novíssima forma de investigação criminal sequer figura no rol (taxativo) das ações (extraordinariamente) permitidas ao governo brasileiro durante o estado de defesa ou de sítio.

À vista deste panorama, decorre, enquanto inexorável, a seguinte conclusão: o cárcere brasileiro se reinventa, deixando assim de funcionar como uma instituição total produtora de subjetividades normalizadas, tal como originalmente pensado por Foucault em "Vigiar e Punir"‘2 , para servir a um novo propósito. É dizer, para funcionar como laboratório (biopolítico) destinado à concepção e teste de novas tecnologias de segurança sobre a vida nua ${ }^{43}$, cuja insacrificabilidade parece ser garantida pelo direito não em respeito à própria condição humana, mas para ilustrar, perante a comunidade dos não desviantes, quem está dentro e quem está fora do círculo de proteção estabelecido pelo ordenamento jurídico ${ }^{44}$.

Daí a ideia de que a Lei Federal n. ${ }^{\circ}$ 12.654/12 funciona como mais uma dessas invenções do laboratório biopolítico que é a política criminal brasileira, mormente porque visa instituir, ao arrepio da lei, um grande varejo de codificações genéticas à disposição dos usos que lhe queira dar o Estado. Nesse desalentador cenário, o indivíduo perde, talvez completamente, o seu estatuto de sujeito de direitos, passando a ser considerado, muito simplesmente, como receptáculo de uma verdade genômica.

Diante de tal análise, cabe finalizar este artigo tentando apontar para alguns desdobramentos possíveis decorrente da vigência do art. $3^{\circ}$ da Lei Federal n. ${ }^{\circ}$ 12.654/12. Uma primeira conclusão que se veste de alerta. A Lei Federal n. ${ }^{\circ}$ 12.654/12 carrega consigo, desde já, tendência que é típica do sistema jurídico do qual é parte integrante, qual seja, a expansão gradual do campo de intervenção do poder punitivo. Com efeito, julgamos estarmos diante de um diploma legal que tem potencial para funcionar como estatuto primeiro de autorização da identificação genética de todos os presos brasileiros, sem exceção. As facilidades, as utilidades persecutórias supostamente engendradas pelas normas da Lei Federal em questão consubstanciam, em larga medida, um convite, já lançado, para que os seus efeitos

$\overline{42}$ FOUCAULT, Michel. Vigiar e Punir: nascimento da prisão. $38^{\mathrm{a}}$ ed. Trad. Raquel Ramalhete. Petrópolis, Rio de Janeiro: Vozes, 2010.

${ }_{33}$ O termo "tecnologia" é empregado neste escrito em referência ao sentido trabalhado por Jonathan Simon em seu "Punishment and the political technologies of the body" (SIMON, Jonathan. Punição e as tecnologias políticas do corpo. Trad. Leandro Ayres França. Revista Sistema Penal \& Violência, v. 5, n. 2, jul/dez. 2013, p. 219-251).

${ }^{44}$ AGAMBEN, Giorgio. Homo Sacer: o poder soberano e a vida nua. Trad. Henrique Burigo. Belo Horizonte: UFMG, 2007, p. 15. 
sejam, ainda que gradualmente, ampliados com o passar do tempo.

Nesse sentido, claro é o exemplo dos substitutos penais no Brasil, os quais, paradoxalmente, apresentados retoricamente como alternativas reais à pena de prisão, acabaram por atrair um número ainda maior de sujeitos para dentro do sistema de justiça criminal, razão pela qual a medida - em vez de se servir como um substitutivo penal - acabou tornando-se, com efeito, um mero prolongamento da prisão ${ }^{45}$.

Poder-se-ia dizer, contudo, que essa previsão peca pelo excesso na medida em que se insere no campo da especulação teórica, todavia não se pode esquecer que os permissivos concebidos pela Lei Federal n. ${ }^{\circ} 12.654$ operam a partir da já conhecida racionalidade jurídico-penal brasileira, uma racionalidade expansionista que tende, como que naturalmente ${ }^{46}$, a alargar as possibilidades de controle penal para além das fronteiras originalmente preconizadas pelo legislador. No ponto, inevitável a referência ao revelador estudo realizado por Laura Frade que, perscrutando as razões que serviram de base para as proposições legislativas em matéria de direito penal durante a $52^{\mathrm{a}}$ legislatura do Congresso Nacional, chegou à seguinte conclusão:

A lei, na legislatura estudada, não esteve voltada à cidadania e sim à exclusão. Não rompeu paradigmas. Os fortaleceu. Não contribuiu para a melhoria da condição social. Expôs a identificação dos elaboradores legais com a elite. A ideia de uma criminalidade fortemente ligada à pobreza ${ }^{47}$.

Pensa-se, pois, por um instante: se os mecanismos jurídicos sustentados pelo aparato estatal punitivo não estão somente comprometidos com a repressão da criminalidade, vez que são igualmente afetados por interesses econômicos ${ }^{48}$, por interesses relacionados de gerenciamento de ilegalidades produzidas pelo próprio

\footnotetext{
${ }^{45}$ AMARAL, Augusto Jobim do. A política da prova e cultura punitiva: a governabilidade inquisitiva do processo penal brasileiro contemporâneo. São Paulo: Almedina, 2014, p. 305.

${ }^{46}$ As duas últimas décadas de legislação penal no Brasil, marcadas pela expansão desmedida do número de Leis Penais, depõem a favor dessa proposição.

${ }^{47}$ FRADE, Laura. Quem mandamos para a prisão? Visões do parlamento sobre a criminalidade. Brasília: Líber Livro, 2008, p. 110. Passados mais de oito anos desde a publicação da referida pesquisa, não existe razão para pensar que o cenário retratado pela autora tenha se alterado. Por esse motivo, as conclusões por ela referendadas permanecem atualíssimas.

${ }^{48}$ RUSCHE, Georg; KIRCHHEIMER, Otto. Punição e Estrutura Social. Tradução, revisão técnica e nota introdutória Gizlene Neder. Rio de Janeiro: Revan, 2004, p. 20.
} 
Estado $^{49} \mathrm{e}$, ainda, por interesses de gestão dos excessos produzidos pelo normal funcionamento da sociedade capitalista ${ }^{50}$, o que garante que a coleta obrigatória de material biológico vá permanecer sendo uma exceção destinada somente aos autores de crimes considerados graves? A propósito disso, vale transcrever o entendimento de Augusto Jobim do Amaral.

Ignorar a dinâmica expansiva do poder punitivo, menosprezar que algum dispositivo que for lançado nestas engrenagens, ainda que dotado das melhores intenções, incorporará e não ficará privado de suas propriedades estruturais, é ficar afeito a um delírio infrutífero. ${ }^{51}$

Eugênio Raúl Zaffaroni, ao analisar a proposta denominada Direito Penal do inimigo ${ }^{52}$ - paradigma no qual a Lei Federal n. ${ }^{0} 12.654$ claramente se insere - propõe duas táticas voltadas à contenção da expansão do poder punitivo, uma de natureza estática e outra de natureza dinâmica. Interessa aqui somente debater somente a primeira, pelos limites que circunscrevem a discussão proposta.

Ao versar sobre a tática estática, o autor observa que não há consenso na comunidade científica acerca da resposta a ser dada ao fenômeno contemporâneo de recrudescimento das práticas penais ${ }^{53}$. Não obstante, entre as várias propostas existentes, desponta - ao menos em termos de reconhecimento internacional àquela conhecida como Direito Penal do Inimigo, formulada pelo jurista alemão

$\overline{49}$ FOUCAULT, Michel. A governamentalidade. In: Microfísica do Poder (1979), organização e tradução de Roberto Machado - 30a reimpressão, Rio de Janeiro: Edições Graal, 2012, pp. 74-75.

${ }^{50}$ WACQUANT, Loïc. Punir os pobres: a nova gestão da miséria da miséria nos Estados Unidos [A onda punitiva]. Trad. Sérgio Lamarão. Rio de Janeiro: Revan, 2003, $3^{\mathrm{a}}$ edição, revista e ampliada, agosto de 2007. $1^{\mathrm{a}}$ reimpressão, março de 2013, p. 17.

${ }^{51}$ AMARAL, Augusto Jobim do. A política da prova e cultura punitiva, p. 307.

${ }^{52}$ Cabe explicar, em apertada síntese, no que consiste a proposta do Direito Penal do Inimigo (Feindstrafre$c h t)$. Com efeito, a conceito designa uma proposta político-criminal que advoga acerca da possibilidade de se estabelecer, desde o plano jurídico-formal, as condiçóes e pressupostos que permitiriam definir quem efetivamente é o destinatário das garantias constitucionais fundamentais e quem não o é. Noutros termos, a teoria de Jakobs preconiza a existência de duas classes específicas de indivíduos, uns detentores da cognição necessária para cumprir com os termos do contrato social e outros desprovidos de tal capacidade. A estes últimos o autor sugere a necessidade de se dispensar um tratamento penal extraordinário, destituído, pois, de garantias constitucionais básicas. Segundo André Luís Callegari e Fernanda Arruda Dutra: "Para Jakobs, es considerado enemigo quien se aleja de modo permanente del Derecho y no ofrece garantías de que va a continuar fiel a las normas mínimas de convivência de la sociedad. Cita como ejemplo el fatídico 11 de septiembre de 2001 como manifestación inequívoca de un acto típico de enemigo. Argumenta que el individuo que no admite ingressar al estado de ciudadanía no puede participar de los beneficios del concepto de persona" (CALLEGARI, André Luís; DUTRA, Fernanda Arruda. "Derecho penal del enemigo y derechos fundamentales". In MELIÁ, Cancio; DÍEZ, Gómez-Jara. Derecho penal del enemigo: el discurso penal de la exclusión. Buenos Aires: Euros Editores, 2006, p. 329).

53 ZAFFARONI, Eugenio Raúl. O inimigo no Direito Penal. Trad. Sérgio Lamarão. Rio de Janeiro: Revan, 2007, $2^{\mathrm{a}}$ edição junho de 2007, 3. ed. dezembro de 2011, p. 155. 
Günther Jakobs, que, por sua vez, defende, a partir do conceito de "não-pessoa" a legalidade da dispensa de um tratamento penal diferenciado, mais rigoroso, para autores de determinados crimes, em especial para os denominados "crimes de terror", tudo a pretexto de "deter o avanço desta tendência que ameaça invadir todo o campo penal" 55 .

Zaffaroni rechaça, contudo, a proposta do jurista alemão, argumentando, em síntese, o seguinte: (i) a dogmática jurídico-penal ainda não concebeu um conceito estrito de inimigo, sendo no mínimo temerário estabelecer tal conceito como dispositivo semântico limitador do exercício das garantias constitucionais fundamentais; (ii) a assunção desse paradigma conceitual implica em um rompimento com a própria teleologia democrática que inspira a ideia mesma do Estado de direito $^{56}$; (iii) calcando-se nas lições do filósofo Heráclito, Zaffaroni lembrará que toda realidade é dinâmica e que nela o poder flui o tempo todo. Vale dizer, não há garantia alguma de que o conceito de "inimigo", uma vez introduzido na ordem jurídica, não vá subvertê-la por completo ao passo em que se constata a ampliação das capacidades conotativas do termo ${ }^{57}$. Tais observações vão de encontro ao que estabelece a normatividade da Lei Federal n. ${ }^{\circ}$ 12.654/12, razão pela qual orientarão as reflexões reservadas para a parte final deste artigo.

\section{CONSIDERAÇÕES FINAIS}

Se a Lei Federal n. ${ }^{0}$ 12.654/12 logrou, não apenas ser promulgada, mas também permanecer produzindo efeitos jurídicos, a despeito da sua aparente ilegalidade, inconstitucionalidade e inconvencionalidade, quer parecer que os fragmentos teóricos anteriormente elencados permitem, desde logo, a realização de algumas prospecções analíticas.

Primeiro, na medida em que se estabelece como consenso - sobretudo

\footnotetext{
${ }_{54}$ É conveniente relembrar, no ponto, os termos empregados por Jakobs para justificar o aludido conceito: "[...] a pessoa, sob a perspectiva do Direito, isto é, a pessoa titular de direitos e obrigações, só pode ser tratada enquanto tal na medida em que conduz as suas ações conforme as expectativas criadas pela norma; se, todavia, se comporta permanentemente como um diabo, a pessoa se converte em um inimigo, é dizer, em uma não -pessoa" (JAKOBS, Günter. Sobre la normativización de la dogmática jurídico-penal. Madrid: Civitas Ediciones, 2003 , p. 54).

55 ZAFFARONI, Eugenio Raúl. Op. Cit., p. 155.

${ }^{56}$ Nesse particular, é tentadora a realização de um exercício de aproximação entre a teoria jurídico-penal de corte funcionalista defendida por Günther Jakobs e as proposições políticas preconizadas por Carl Schmitt.

${ }^{57}$ ZAFFARONI, Eugenio Raúl. Op. Cit., pp. 166-167.
} 
no âmbito da comunidade jurídica - a hipótese da coleta compulsória de material genético como forma de identificação criminal pode, futuramente, vir ser indiscriminadamente ampliada para além dos limites originalmente previstos. Tal parece ser o caso tanto em função da conhecida retórica punitivista que caracteriza a política criminal brasileira, como em razão da típica flexibilidade do ordenamento jurídico-penal brasileiro.

Ainda, e como já afirmado ao longo do segundo tópico deste artigo, a assunção acrítica dos instrumentos normativos criados pela Lei Federal n. ${ }^{0}$ 12.654/12 dá ensejo a um perigo político sem precedentes, qual seja, a normatização do entendimento de que determinados direitos e garantias fundamentais podem (ou pior: devem) ser instrumentalizados segundo os desígnios securitários idealizados pela elite burocrática do Estado. Ora, quem está a serviço de quem? Eis um questionamento que parece oportuno suscitar.

Deste modo, embora seja necessário depositar alguma esperança na potência do pensamento crítico, firma-se, por ora, posição bastante pessimista em relação à análise da potência normativa e simbólica da Lei Federal n. ${ }^{\circ}$ 12.654/2012, uma vez que ela claramente reinventa, em termos "tanatopolíticos" corpo dos condenados, relegando-os à condição antipolítica da "vida nua"59 ("zoé"), uma existência privada, sempre em nome de uma necessidade que não conhece limites, da capacidade de usufruir dos mais elementares direitos constituintes da condição de pessoa humana.

\footnotetext{
${ }^{58}$ No tópico em que discute mais abertamente a figura do "Homo Sacer", Agamben argumentará que vivemos, na atual quadra da história, sob o jugo de um novo paradigma de governo. Se para Foucault a modernidade se caracteriza pela derrocada do domínio despótico e pela ascensão de um governo biopolítico baseado na ideia de desenvolvimento de técnicas e estratégicas voltadas à promoção e ao disciplinamento das potencialidades produtivas da vida humana, para Agamben, atualidade é mais bem conhecida pela derrocada da biopolítica e pela consequente emergência de práticas e discursos que guindam a morte, e não mais da vida, à condição de realidade organizadora das estratégias de poder e/ou dominação. Neste sentido, quer parecer que o termo tanatopolítica representa, muito simplesmente, a retomada de um projeto político que nunca foi realmente abandado, um projeto de poder baseado na revitalização dos poderes de intervenção do soberano sobre a vida, que agora, tal como sucedia no (não tão) passado despótico, se arrogam, novamente, da prerrogativa de decidir não somente quem deve viver, mas também qual vida merece ser vivida (AGAMBEN, Giorgio. Homo Sacer: O poder soberano e a vida nua. Trad. Henrique Burigo. Belo Horizonte: UFMG, 2007, p. 132).

${ }^{59}$ Ao discorrer acerca das políticas de exceção gestadas e importadas pelos Estados Unidos pós-11 de setembro, Agamben argumentará que a concepção de vida humana vem sendo lentamente reconfigurada pela sedimentação, no imaginário social, da figura da vida nua, uma vida que foi representada pela cultura grega sob o conceito de "zoé", uma vida desprovida de importância política, uma vida reduzida ao aspecto puramente biológico. Transposto o conceito para o âmbito do debate político-criminal, embora não sendo possível reduzi-lo somente a tal esfera de análise, inevitável não estabelecer um paralelo entre a figura da mera vida, referida por Agamben, e a condição existencial de milhares sujeitos cujos corpos permanecem depositados, a despeito de qualquer consideração ético-política, nas masmorras que constituem o sistema penitenciário brasileiro (AGAMBEN, Giorgio. Homo Sacer: O poder soberano e a vida nua. Op. Cit. p. 9).
} 


\section{REFERÊNCIAS}

AGAMBEN, Giorgio. Estado de Exceção. 2. ed. rev. Trad. Iraci D. Poleti. São Paulo: Boitempo, 2014. (Col. Estado de sítio).

AGAMBEN, Giorgio. Homo Sacer: o poder soberano e a vida nua. Trad. Henrique Burigo. Belo Horizonte: UFMG, 2007.

AGAMBEN, Giorgio. O que é o dispositivo?. In: O QUE É O CONTEMPORÂNEO e outros ensaios. Trad. Vinícius Nicastro Honesko. Chapecó: Santa Catarina: Argos, 2009, p. 25-54.

AMARAL, AugustoJobim do. A política da prova e cultura punitiva: agovernabilidade inquisitiva do processo penal brasileiro contemporâneo. São Paulo: Almedina, 2014.

BARATTA, Alessandro. Criminologia Crítica e Crítica do Direito Penal. Trad. Juarez Cirino dos Santos. 3. ed. Rio de Janeiro: Revan: Instituto Carioca de Criminologia, 2002.

BENJAMIN, Walter. Para uma crítica da violência. In: ESCRITOS sobre mito e linguagem (1915-1921). Trad. Susana Kampff e Ernani Chaves. São Paulo: Ed. 34, 2011.

BRASIL. Supremo Tribunal Federal. Tribunal Pleno. Repercussão Geral no Recurso Extraordinário n. ${ }^{0}$ 973837. Relator: Ministro Gilmar Mendes. Brasília, 11 de outubro de 2016. Disponível em: <http://www.stf.jus.br>. Acesso em: 15 nov. 2016.

BRASIL. Constituição Brasileira (1988). Constituição da República Federativa do Brasil. Brasília, DF: Senado Federal: Centro Gráfico, 1988, 292 p.

BRASIL. Lei Federal n. ${ }^{\circ} 12.65428$ de maio de 2012. Altera as Leis nos 12.037, de 10 de outubro de 2009, e 7.210, de 11 de julho de 1984 - Lei de Execução Penal, para prever a coleta de perfil genético como forma de identificação criminal, e dá outras providências. Diário Oficial [da] República Federativa do Brasil, Braślia, DF, 29 mai. 2012. 
BRASIL. Lei Federal n. ${ }^{\circ} 7.210$ de 11 de julho de 1984. Institui a Lei de Execução Penal. Diário Oficial [da] República Federativa do Brasil, Brasília, DF, 13 jul. 1984 .

BRASIL. Lei Federal n. ${ }^{\circ} 8.072$ de 25 de julho de 1990. Dispõe sobre os crimes hediondos, nos termos do art. $5^{\circ}$, inciso XLIII, da Constituição Federal, e determina outras providências. Diário Oficial [da] República Federativa do Brasil, Brasília, DF, 26 jul. 1990.

CALLEGARI, André Luís; DUTRA, Fernanda Arruda. Derecho penal del enemigo y derechos fundamentales. In: MELIÁ, Cancio; DÍEZ, Gómez-Jara. Derecho penal del enemigo: el discurso penal de la exclusión. Buenos Aires: Euros Editores, 2006.

CHIGNOLA, Sandro. Sobre o dispositivo: Foucault, Agamben, Deleuze. Tradução de Sandra Dall Onder. Cadernos IHU Ideias, Instituto Humanitas Unisinos, São Leopoldo, v. 12. n. ${ }^{\circ}$ 214, 2014.

DELEUZE, Gilles. Que és un dispositivo? In: BALIBAR, Etinenne et al (Org.). Michel Foucault, filósofo. Barcelona: Gedisa, 1999. p. 155-163.

FOUCAULT, Michel. A governamentalidade. In Microfísica do Poder (1979), organização e tradução de Roberto Machado, Rio de Janeiro: Graal, 2012, p. 277 295.

FOUCAULT, Michel. Segurança, Território e População. Curso do Còllege de France (1977-1978). Trad. Eduardo Brandão. São Paulo: Martins Fontes, 2008.

FOUCAULT, Michel. Sobre a história da sexualidade. In: MACHADO, Roberto. (Org.). Microfísica do poder (1979). Rio de Janeiro: Graal, 2012, p. 243-276.

FOUCAULT, Michel. Vigiar e Punir: nascimento da prisão. Trad. Raquel Ramalhete. 38. ed. Petrópolis, Rio de Jaeniro: Vozes, 2010.

FRADE, Laura. Quem mandamos para a prisão?: Visões do parlamento sobre a criminalidade. Brasília: Líber Livro, 2008. 
e Civil. Trad. Rosina D’Angina. São Paulo: Martin Claret, 2014.

JAKOBS, Günter. Sobre la normativización de la dogmática jurídico-penal. Madrid: Civitas Ediciones, 2003.

MOUFFE, Chantal. The Democratic Paradox. Verso: London, 2000.

QUEIJO, Maria Elizabeth. O princípio nemo tenetur se detegere e a coleta de material genético: identificação criminal ou colaboração na produção da prova?. Boletim Instituto Brasileiro de Ciências Criminais, v. 21, n. ${ }^{\circ}$ 250, set. 2013.

REVEL, Judith. Michel Foucault: conceitos essenciais. Tradução Maria do Rosário Gregolin, Nilton Milanez, Carlos Piovesani. São Carlos: Claraluz, 2005.

RUSCHE, Georg; KIRCHHEIMER, Otto. Punição e Estrutura Social. Tradução, revisão técnica e nota introdutória Gizlene Neder. Rio de Janeiro: Revan, 2004.

SALAS, Denis. La Voluntè de Punir: Essai sur le Populisme Pénal. Paris: Hachette, 2005.

SCHIOCCHET, Taysa. O humano entre o direito a e genética: pressupostos para o debate legislativo acerca das implicações jurídicas concernentes à criação de bancos de perfis genéticos para fins de persecução criminal. In: CALLEGARI, André Luis et al. (Org.). Constituição, sistemas sociais e hermenêutica: Anuário do PPG em Direito da Unisinos - Mestrado e Doutorado. Porto Alegre: Livraria do Advogado, 2011 , v. 8 , p. 285-302.

SCHMITT, Carl. Teologia Política. In: A CRISE da democracia parlamentar. Trad. Inês Lohauer. São Paulo: Scritta, 1996.

SIMON, Jonathan. Punição e as tecnologias políticas do corpo. Trad. Leandro Ayres França. In Revista Sistema Penal \& Violência, v. 5, n. 2, p. 219-251, jul./dez. 2013.

WACQUANT, Loïc. Punir os pobres: a nova gestão da miséria da miséria nos Estados Unidos [A onda punitiva]. Trad. Sérgio Lamarão. 3. ed. rev. e ampl. Rio de Janeiro: Revan, 2003. 
ZAFFARONI, Eugenio Raúl. O inimigo no Direito Penal. Trad. Sérgio Lamarão. Rio de Janeiro: Revan, 2007.

Recebido em: 17 de agosto de 2017 Aceito em: 13 de dezembro de 2017 
